\title{
Exploring How the Drinking Frequency Influence the Work Intensity Among the Youth: Evidence from National Longitudinal Survey of Youth (NLSY)
}

\author{
Yixuan Yan ${ }^{1, a}$, Sizhe $\mathrm{Liu}^{2, \mathrm{~b}}$, Yuanmei Cao ${ }^{3, \mathrm{c}}$, Ao Wang ${ }^{4, \mathrm{~d}}$ \\ ${ }^{1}$ Queen's University, Department of Economics, K7L 3N6, 99 University Ave, Kingston ON, Canada \\ ${ }^{2}$ Queen's University, Department of Economics, K7L 3N6, 99 University Ave, Kingston ON, Canada \\ ${ }^{3}$ Lancaster university, Department of Accounting and Finance, LA1 4YW, Lancashire, United Kingdom \\ ${ }^{4}$ Hong Kong Shue Yan University, Economics and Finance, 999077, 10 Wai Tsui Crescent, Braemar Hill, North \\ Point, Hong Kong China \\ a17yy57@queensu.ca \\ b17sl91@queensu.ca \\ ${ }^{c}$ caoy14@lancaster.ac.uk \\ d189001@hksyu.edu.hk
}

\begin{abstract}
In the past research, many scholars have been studying the harm of drinking. In this paper, through the method of establishing econometric model, by comparing the test statistics of each variable in the stepwise regression model, the stepwise regression analysis method is used to find out the most statistically significant model and study the relationship between the drinking frequency and the work intensity. Additionally, exploring how drinking frequency and working hours impact the economic development. Many other variables are selected to study the significance between themselves and the work intensity. The endogenous problem is also studied by using the appropriate tool variable "company" to solve this problem. Finally, it is concluded that there is a positive correlation between the work intensity and the drinking frequency.
\end{abstract}

Keywords: Labour Economics, Alcohol Use, Work Intensity, Economic Development.

\section{INTRODUCTION}

People always drink for various reasons. Some are for social etiquette, some are for work entertainment, and some are for escapism. This is because that under the paralysis of alcohol, those who are unhappy in life can temporarily forget their troubles. Drinking has become a phenomenon that cannot be ignored in modern society.

For people at work, the different drinking frequency affects the working intensity to different degrees. According to a study conducted by three Spanish universities in 2014, moderate drinking can actually help people live longer. What is more, the study lists various of advantages of moderate and routine drinking and especially points out the positive effects on those who are going to work. This study presents the strengths of ergophobia from physiology and psychology seperately. In physical aspects, moderate frequency of drinking can actually help people live longer. As Wurdak et al. (2016) mentioned in their research, "People who drink moderately are less likely to suffer from the most common types of the heart disease than people who are excessively drink alcohol and do not drink alcohol." [1] The reason is that the chemistry of alcohol in the blood has "protective effect" on the heart. Moreover, moderate drinking frequency can also prevent other different kinds of illness from happening ahead of time, such as diabetes, common cold, and Alzheimer's disease. For someone who need to spend large amount of time working, the occurrence of physical disease in the working time can influence the working intensity largely since it is very essential for them to extend the relaxation and treating time. However, for those who moderately drinks, it is more likely to reduce these problems due to healthier body. In psychology aspects, the research done by the school of public health in the Harvard University shows that those who drink in moderation will increase happiness and "a pleasant and carefree" feeling. [2] A relax mood can make the positive working attitude 
possible, thereby improves the working intensity in large degree.

It can be argued that excessive or even high frequent drinking must be harmful to bodies not only in physiology but also in psychology aspects, thereby reducing the working intensity for people at the work. Wurdak et al. (2016) also reported that "people who drinking excessively or do not drink alcohol are more likely to feel nervous, depressed and self-conscious than those who drink moderately, and thus have a higher rate of clinical depression." [3] Some people are under very terrible work pressure, thus, they view drinking as the effective approach of releasing stress and escaping from the reality. What is worse, it is very likely that the heavier work pressure, the higher drinking frequency of the drinking for those workers is. However, Zawn Villines (2019) noted in the medical research, long-term high frequent drinking can cause alcoholism and brain cell damage, thus does harm to the mental health and may cause someone be unable to concentrate at work, or even lose their work abilities. [4] Therefore, the high frequency of drinking may reduce the working intensity to a certain extent. In physiology, long-term high frequency drinking will easily lead to bond and muscle diseases, as well as atrophy of limbs, which results in possible loss of someone's all labour, thus the working intensity may be lost thoroughly.

As alcohol use becomes one of the important factors influence the labour participation and in turn the economic development. It is worthy to discuss how the alcohol consumption affect the labour outcomes, through specifically looking at the relationship between work intensity and drinking frequency. In this paper, by studying the longitudinal data set in the United States in 1989 and 1994, the research is mainly conducted from two aspects. First, we will study the relationship between working hours and drinking problems, which in turn affecting the economic outcomes. Secondly, we will analyze the inner relationship between drunk work and heavy work. In the future, the method of analyzing mediating effects can also be used to specifically find how alcohol affects human health and thus affects the work intensity. As the result, our paper finds the positive relationship between drink frequency and work intensity. Additionally, the alcohol use would indirectly affect the economic growth in a positive direction.

\section{DATA AND MODEL}

\subsection{Data}

The paper uses the dataset that comes from the National Longitudinal Survey of Youth (NLSY) in 1989 and 1994, which contained information about the labour market outcomes and substance uses of a representative population of youth in the US. In 1989, 16,000 young adults aged 24 to 37 years participated in the survey program. In 1994, the same group of adults was reinterviewed, at the age from 29 to 37 years. Unlike the other longitudinal dataset, the NLSY has dated the issue of non-randomness of attrition. [5] To process the dataset, the paper firstly eliminated the unusual numbers and potential errors, for instance, the workers have worked for a long term but receive no wages in the past calendar year, and vice versa. However, we found the results and impacts gained from the original dataset and the processed dataset are almost indifferent. Thus, we conclude those errors impact our exploration insignificantly, and it can ignore them.

\subsection{Measures}

According to the relevant literature and the feasibility of the dataset, the work intensity is based on the question about the "total number of hours worked in the past calendar year", and "the total number of weeks worked in the past calendar year". In the datasets, there is no index to show the intensity of working, so the paper uses the total hours in the year divide by the total number of weeks to gain the work intensity in the unit of "hours per week". The independent variable of drink frequency is represented by a categorical variable "drnk6m", which indicates the number of times in the past month that the individual had more than six drinks in one sitting. The integer number " 0 " to " 5 " indicates the individual's drinking frequency of having six drinks in the one sitting in the last month is less than ten times, which would be classified as the "moderate drinker". However, the number " 6 " indicates the individual had ten times or more for having six drinks in one sitting, which is classified as the "heavy drinker". Also, the paper uses a dummy variable "drnkev" to show if the individual has ever had a drink, and "drnkev" = 1 if the worker has ever had a drink, and $=0$ otherwise.

The paper uses the stepwise regression analysis to find the most statistically significant model by comparing the test statistics of each variable in the stepwise regression models. The additional control variables for the multiple linear regression model in the paper are: (1) The log value of total wage and salary income in the past calendar year ("Inwgsal"). The income is highly tied with work intensity since it works as an incentive for labours to work. We would also use this indicator to partially represent the economic development. (2) Regions ("region"), this is the categorical variable to classify the living locations of individuals into "Northeast", "North Central", "South", and "West". Since the different regions in the US might have distinctive regulations and requirements for the working intensity of each worker. (3) Health condition ("health"). This indicator shows whether the individual has a health problem that limits work intensity. The health condition of individuals directly relates to the availability of high-intensity working. (4) Family size 
("famsz") shows the number of individuals in a family. The family size can also influence an individual's decision of whether participating in the labour force or not. The variable "Inwgsal" gets the highest t-Statistics in the first round of forwarding selection, followed by variables "region", "health" and "family size".

Table 1. shows the sample sizes are different among the variables. There are 13,289 observations for "work intensity". The drinking frequency; indicator for having drink or not; region; and family size are in the same sample size, which is at 14,781 . The sample indicator of total income The highest work intensity for the interviewed individual is at " 168 hours of working in one week", and the lowest work intensity is at only 1 hour of working in a week. After taking the log value for the total wage and salary income in the past calendar year, the number declined where the maximum value is around 13.3 and the minimum value is at zero. The maximum value of the drinking frequency is one when the individual is a heavy drinker, otherwise, the minimum is at zero when the individual is a moderate drinker.

Table 1. The Variable Descriptive Statistics

\begin{tabular}{|l|c|c|c|c|c|c|}
\hline Variables & Symbols & Observations & Mean & Maximum & Minimum & Std.Dev. \\
\hline $\begin{array}{l}\text { Work } \\
\text { intensity }\end{array}$ & workst & 13,289 & 42.17449 & 168 & 1 & 11.23972 \\
\hline $\begin{array}{l}\text { Drink } \\
\text { frequency }\end{array}$ & drnk6m & 14,781 & 0.8168 & 6 & 0 & 1.4756 \\
\hline $\begin{array}{l}\text { Log of total } \\
\text { wage }\end{array}$ & Inwgsal & 13,357 & 9.5601 & 13.3207 & 2.3026 & 1.0468 \\
\hline $\begin{array}{l}\text { Ever had a } \\
\text { drink }\end{array}$ & dnkev & 14,781 & 0.9549 & 1 & 0 & 0.2074 \\
\hline Region & region & 14,781 & 2.6081 & 4 & 1 & 0.9934 \\
\hline $\begin{array}{l}\text { Health } \\
\text { condition }\end{array}$ & health & 14,596 & 0.052 & 1 & 0 & 0.2220 \\
\hline Family size & famsz & 14,781 & 3.0733 & 14 & 1 & 1.5884 \\
\hline
\end{tabular}

Before constructing the econometric model, the paper uses the method of Pearson correlation to test the correlations among the variables to ensure the rationality of the model and examine the strength of the linear relationships. The test result is shown in Table2., and the key independent variable of drink frequency ("drnk6m") is positively correlated with an individual's work intensity at the significant level of 0.05 . The rest four independent variables are significantly correlated, except the variable of the region. There were some substantial differences in drinking for various regions in the United State earlier before 1989. However, Klein and Pittman' study (2009), [6] based on the sample of the US youth in 1986, finding there is little evidence for evident distinctions in alcohol consumptions in various areas. Klein and Pittman concluded the result is possibly caused by urbanization, high mobility rate, and greater recognition of alcohol consumption in the US.

Table 2. Pearson Correlation Test Results

\begin{tabular}{|c|c|c|c|c|c|c|c|}
\hline Variables & workst & Inwgsal & drnk6m & drnkev & region & health & famsz \\
\hline workst & 1.0000 & & & & & & \\
\hline drnk6m & $0.0711^{*}$ & 1.0000 & & & & & \\
\hline Inwgsal & $0.3956^{*}$ & 0.0001 & 1.0000 & & & & \\
\hline drnkev & $0.0298^{*}$ & $0.1202^{*}$ & $0.0634^{*}$ & 1.0000 & & & \\
\hline region & 0.0156 & $-0.0281^{*}$ & $-0.0592^{*}$ & $-0.0384^{*}$ & 1.0000 & & \\
\hline health & $-0.0363^{*}$ & -0.0101 & $-0.1081^{*}$ & -0.136 & 0.0089 & 1.0000 & \\
\hline famsz & $-0.0752^{*}$ & $-0.0816^{*}$ & $-0.1288^{*}$ & $-0.0955^{*}$ & $0.0185^{*}$ & -0.035 & 1.0000 \\
\hline
\end{tabular}

(* means the correlation coefficient is statistically significant at 0.05 )

\subsection{Model and Result}

According to the stepwise regression analysis and the Pearson correlation analysis, there are some impacts of drink frequency on the individual work intensity. The paper constructs a multiple linear regression model to make an in-depth exploration of the impact level. 
workst $=\beta_{0}+\beta_{1}$ drnk6m $+\beta_{2}$ lnwgsal + $\beta_{3}$ drnkev $+\beta_{4}$ region $+\beta_{5}$ health $+\beta_{6}$ famsz $+\mu_{0}$

Where is the $\beta_{0}$ is the constant, $\beta_{1}, \beta_{2}, \beta_{3}, \beta_{4}, \beta_{5}, \beta_{6}$ are coefficient numbers, and $\mu_{0}$ includes the random errors.

The regression result of Table 3 shows the significance of parameters and the significance of the model. The drink frequency, log value of the total wage, and region positively impact the individual's work intensity, and almost all coefficients of these independent variables are statistically significant at the significant level of 0.01 , except the variable "drnkev" and "health". To be specific, holding the other variables constant, the work intensity is estimated to increase by approximately 0.53 hours for one additional occasion having six or more drinks in one sitting. Hence, we can conclude that the more frequent and heavier drinking habit, the more workload the individual faced. The relationship between work intensity and drink frequency is also statistically significant because the p-value is small and we can reject the null hypothesis at the level of 0.01 . The result of the relationship is inconsistent with our first assumption which is about the heavy drinking habit will decrease the work intensity due to the limitations in health condition and work efficiency. The influence of wage on the work intensity is relatively strong with the coefficient is around 4.40 , and the relationship is also statistically significant at 0.01 . It makes the intuitive sense that higher reward would incentive the workers to put more effort in working. The variable region also positively impacts the work intensity of individual work at a significant level of
0.01 . With the different regions, including the Northeast, North Central, South, and West of the US, the influence of regions on the work intensity are around 0.47 hours, 0.94 hours, 1.41 hours, and 1.88 hours, respectively. According to the result, the individuals who come from the west will be impacted the most. The variable "health" also positively affects the work intensity, since the better the health condition, the more capabilities the workers have. According to the result of regression, if the individual does not have a health problem that limits the amount of work to be done (dummy variable $=1$ ), the working hour of this individual would increase by about 0.50 hours. Differently, the variable "drnkev" and "famsz" negatively impact the work intensity. The situation of statistical insignificance might be a result of endogeneity problem. The endogeneity would cause the bias and inconsistence in estimation, which mislead our result. Therefore, we will test and deal with the endogeneity bias in the next section. To interpret the possibility that causes the insignificance of "famsz", the large family size might disincentive individuals to take part in the labour force. People are more likely to "enjoy the fruits of others' work" as there are abundant working people in the family, who get adequate income to support the whole family. The result shows that the one additional person increase in the number of family members would decrease the individual's work intensity by 0.14 hours per week. For the significance of the model, the F-statistics is at 427.56 and the probability value is at 0 , which shows that the model constructed here is also statistically significant.

Table 3. The Estimation Result of the Regression Model

\begin{tabular}{|c|c|c|c|c|}
\hline Variable & Coefficient & Std. Error & t-Statistic & Prob. \\
\hline C & -0.9824 & 1.0343 & -0.95 & 0.34 \\
\hline drnk6m & 0.5251 & 0.0603 & 8.71 & $0.00^{\star \star *}$ \\
\hline Inwgsal & 4.3952 & 0.0901 & 48.80 & $0.00^{\star \star *}$ \\
\hline drnkev & -0.1483 & 0.4600 & -0.32 & 0.75 \\
\hline region & 0.4696 & 0.0899 & 5.23 & $0.00^{\star * *}$ \\
\hline health & 0.5026 & 0.4415 & 1.14 & 0.26 \\
\hline famsz & -0.1444 & 00576 & -2.51 & $0.01^{\text {*** }}$ \\
\hline SS Model & 267029.722 & \multicolumn{2}{|c|}{ Number of Obs } & 13,157 \\
\hline SS Residual & 1368789.89 & \multicolumn{2}{|c|}{ F-statistic } & 427.56 \\
\hline SS Total & 1635819.61 & \multicolumn{2}{|c|}{ Prob $>$ F } & 0.0000 \\
\hline Root MSE & 10.202 & \multicolumn{2}{|c|}{ R-squared } & 0.1632 \\
\hline & & \multicolumn{2}{|c|}{ Adj R-squared } & 0.0698 \\
\hline
\end{tabular}

(*** means the estimated coefficient is statistically significant at 0.01)

To find the potential effect of alcohol use and work intensity of individuals on the economic development, we separately constructed two simple linear regression models to find the relationships. The log value of wages is used to represent one factor of the gross domestic product (GDP). According to the income approach for calculating GDP, the GDP can be computed by the sum of total national income, sales taxes, depreciation, and foreign factor income (Zeder 2020). [7] Hence, the total income we applied in our empirical analysis can be regarded as an important factor promoting the GDP of a country. Following this logic, the first simple regression model is:

$$
\text { lnwgsal }=\alpha_{0}+\alpha_{1} d r n k 6 m+\varepsilon_{0}
$$


Where $\alpha_{0}, \alpha_{1}$ are the coefficients, and $\varepsilon_{0}$ is the random error. The coefficient result shows that the more frequent drinking, the higher total income. However, the impact is not remarkable at all, since the coefficient number is close to zero and we cannot reject the null hypothesis at 0.05 . Thus, there is not a direct relationship between drinking frequency and income level. The income level is more likely to be influenced by how many variations in people's drinking habits. According to the health research done by the National Public Radio (NPR), the low-income workers usually have more variations in their drinking habits than high-income workers (2015). [8]

The second simple regression model is:

$$
\text { lnwgsal }=\gamma_{0}+\gamma_{1} \text { workst }+\varepsilon_{1}
$$

Where $\gamma_{0}, \gamma_{1}$ are the coefficients, and $\varepsilon_{1}$ is the random error. The regression result shows a statistically significant positive relationship between work intensity and total income. To be more exact, as the work hour increased by one hour, the income of this work is estimated to increase by 0.036 dollars. Therefore, the more working hours would increase the total wages, and eventually benefits the economic development. To sum up, as the drinking frequency increases (in Table 3.), the working hours will increase, which would rise the total wages and in turn promote the economic development to some extent.

\section{INSTRUMENTAL VARIABLE ANALYSIS}

Endogenous problem. The first analysis result led us to figure out the endogenous problem. We found, the relationship between working intensity and drinking are closely tied together. When people have high working intensity for a long period of time, the most common (and obvious) result of hard-working is a lack of adequate sleep. In the U.S., roughly $40 \%$ of employees experience sleep loss. In fact, so many people are not getting enough sleep that the CDC has declared it a public health emergency. [9] In this case, throughout the day, we draw on a limited store of mental energy. Some people call this willpower: the forceful use of mental energy to get at a goal. When our willpower stores get used up, we get tired. The analogy here is like a tank of gas; when it's empty, the tank sputters out. Moreover, the lack of sleep reduces the mental energy produced by our body, which leads to a result. That is people would easily get tired and can't finish their work. We become anxious and fretful.

According to Mulford and Miller, one big category of motivation for drinking alcohol is called "personal effect motives" which is an overarching category that includes drinking to cope with, escape, avoid, or control negative emotions. Drinking for these reasons is a form of negative reinforcement. [10] Therefore, when people become stressful by heavy working, they tend to drink to relax. Meanwhile, for some people, alcohol gives off feelings of pleasure, encouraging the brain to repeat the behaviour. All of these lead to a relationship is the higher intensity people work the more frequently they drink. It is an endogenous problem in our regression model.

Instrumental Variables. The instrument variables we use are called "company" which is consisted of whether the person got their parents to stay with and educate them when they were 14 years old. Plain and simple, teens want to fit in. Peer pressure factors heavily into the decision-making process, especially regarding serious issues such as drinking alcohol and experimenting with drugs. As parents, they have an inherent desire to protect their child from risky influences that have the potential to harm them. However, when people get lack of parents' right help at this special time which called "adolescent rebellion", it is not surprising that they would form some bad habits like alcoholism. Therefore, we choose these variables as an instrument to help us eliminate the influence of endogenous problems.

Table 4. The Estimation Results of the Instrumental variable Model

\begin{tabular}{|c|c|c|c|c|}
\hline Variable & Coefficient & Std. Error & Z-Statistic & Prob. \\
\hline C & -6.8344 & 2.9243 & -2.34 & 0.019 \\
\hline drnk6m & 10.2925 & 3.8616 & 2.67 & $0.0000^{* * *}$ \\
\hline Inwgsal & 4.6718 & 0.1904 & 24.54 & $0.0000^{* * *}$ \\
\hline drnkev & -8.3140 & 3.3239 & -2.50 & 0.012 \\
\hline region & 0.8137 & 0.2066 & 3.94 & $0.000^{* * *}$ \\
\hline health & 1.8133 & 0.9230 & 1.96 & 0.049 \\
\hline Famsz & 0.4846 & 0.2678 & 1.81 & 0.07 \\
\hline
\end{tabular}

(*** means the estimated coefficient is statistically significant at 0.01 )

Table 4. shows the data result after eliminated the endogenous problem. All variables are significant as we predict before. The result shows that the drinker's working time per week has average -8.3140 hours less than others. Similarly, it is quite interesting that heavy drink has a positive effect on working intensity that one drink increased there would be 10.2925 working time increase simultaneously. 


\section{CONCLUSION}

Overall, it is interesting that there is a positive relationship between working intensity and drinking frequency. Moreover, we also found that the higher drinking frequency can indirectly promote the economic growth through increasing working hours and then total salaries. However, there is no direct relationship between drinking frequency and total income. Our findings in general are noteworthy in two aspects. First, we observe a relationship between working time and the drinking problems, independent of general drinking frequency. We also discuss about how alcohol use and work intensity would impact the economic growth. Second, we analyzed the inner relationship of drinking and heavy work, eliminating the problem by creating valuable instrument.

For the problem of positive relationship between the working intensity and the drinking amount. We guess this problem is resulted from the difference in the frequency of drinking. For instance, for some people, drinking is also their part of job. More common issue is to take part in company sponsored events, people have to drink with their colleagues and boss for achieving a good relationship. At this point, drinking more alcohol is necessary. It is also a weakness of our research that we cannot determine what is the reason for drinking. This conclusion is also co-related with the idea proposed by Paschall MJ, [11] that the employee would like to drink with higher working intensity compared to others due to the mentality issue. Lastly, future researchers are encouraged to find the direct relationship between drink frequency and total income by adding more variables related to the variations in drinking habits

\section{REFERENCES}

[1] Wurdak ,M.,Kuntsche,E.(2015) Effectiveness of a drinking-motive-tailored emergency-room intervention among adolescents admitted to hospital due to acute alcohol intoxication - A randomized controlled trial.Available at:https://doiorg.ezproxy.lancs.ac.uk/10.1016/j.pmedr.2015.12. 009

[2] Alcohol: Balancing Risks and Benefits. (2020, November 12). The Nutrition Source. https://www.hsph.harvard.edu/nutritionsource/heal thy-drinks/drinks-to-consume-inmoderation/alcohol-full-story/

[3] Wurdak ,M.,Kuntsche,E.(2015) Effectiveness of a drinking-motive-tailored emergency-room intervention among adolescents admitted to hospital due to acute alcohol intoxication - A randomized controlled trial.Available at:https://doiorg.ezproxy.lancs.ac.uk/10.1016/j.pmedr.2015.12. 009
[4] Villines, Z. (2019, July 3). What to know about alcohol and brain damage. Medical News Today. https://www.medicalnewstoday.com/articles/32564 4

[5] Moore, W., Pedlow, S., Krishnamurty, P., Wolter, K., \& Chicago, I. L. (2000). National longitudinal survey of youth 1997 (NLSY97). National Opinion Research Center, Chicago, IL, 254.

[6] Klein, H., \& Pittman, D. J. (1993). Regional Differences in Alcohol Consumption and Drinkers' Attitudes toward Drinking. The American Journal of Drug and Alcohol Abuse, 19(4), 523-538. https://doi.org/10.3109/00952999309001640

[7] Zeder, R. (2020, June 26). How to Calculate GDP Using the Income Approach. Quickonomics. https://quickonomics.com/how-to-calculate-gdpusing-the-income-approach/

[8] Partnership to End Addiction. (2015, March 18). Income Level May Influence a Person's Drinking Habits: Study. https://drugfree.org/drug-andalcohol-news/income-level-may-influencepersons-drinking-habitsstudy/\#:\%7E:text=A\%20person's\%20income\%201 evel\%20may,drink\%2C\%20a\%20new\%20study\% 20suggests.\&text=People $\% 20$ with $\% 20$ higher $\% 20 \mathrm{i}$ ncomes $\% 2 \mathrm{C} \% 20$ in, they $\% 20$ consume $\% 2 \mathrm{C} \% 20$ acc ording $\% 20$ to $\% 20$ NPR.

[9] Rodriguez, J. (2016, December 9). CDC Declares Sleep Disorders a Public Health Epidemic. Advanced Sleep Medicine Services, Inc. https://www.sleepdr.com/the-sleep-blog/cdcdeclares-sleep-disorders-a-public-health-epidemic/

[10]Abbey, A., Smith, M. J., \& Scott, R. O. (1993). The relationship between reasons for drinking alcohol and alcohol consumption: An interactional approach. Addictive Behaviors, 18(6), 659-670. https://doi.org/10.1016/0306-4603(93)90019-6

[11]Paschall, M. J., Flewelling, R. L., \& Russell, T. (2004). Why is work intensity associated with heavy alcohol use among adolescents? Journal of Adolescent Health, 34(1), 79-87. https://doi.org/10.1016/s1054-139x(03)00206-4 